\title{
On inverse sampling without replacement
}

\author{
M. Ruiz Espejo • H. P. Singh • S. Saxena
}

Published online: 26 February 2009

(C) Springer-Verlag 2009

\section{Acknowledgement of Priority}

On behalf of the authors, the Editorial Board of Statistical Papers acknowledges that much of the development and results of

Ruiz Espejo M., Singh, H.P. and Saxena, S.:

On the inverse sampling without replacement.

Statistical Papers 49, pp. 133-137 (2008)

doi:10.1007/s00362-006-0376-X

are also achieved in:

\section{Rohatgi, V.K. and Saleh, A.K. Md. Ehsanes:}

An introduction to probability and statistics.

2nd ed. Wiley, New York, 2001 (pp. 193-194)

Götz Trenkler, Coordinating Editor, Statistical Papers

Fakultät Statistik, Technische Universität Dortmund

Vogelpothsweg 87, 44221 Dortmund, Germany

e-mail: trenkler@statistik.uni-dortmund.de

The online version of the original article can be found under doi:10.1007/s00362-006-0376-X.

M. R. Espejo

Departamento de Matemáticas Fundamentales, UNED and UPCO,

Apartado 19207, 28080 Madrid, Spain

H. P. Singh

School of Studies in Statistics, Vikram University, Ujjain 456010, Madhya Pradesh, India

S. Saxena

Institute of Management, Nirma University of Science and Technology,

Ahmedabad 382 481, Gujarat, India 